\title{
Uso y disfrute del agua en la Villa Romana de Puente de La Olmilla (Albaladejo, Ciudad Real). El aprovechamiento hídrico en el Mundo Romano
}

\author{
The use and enjoy of the water in the Roman Villa of Puente \\ de La Olmilla (Albaladejo, Ciudad Real). The procurement \\ of the water in the Roman World
}

\author{
Carmen García Bueno*
}

\section{RESUMEN}

El abastecimiento hídrico de esta villa se proveía mediante varios conductos cerámicos, parcialmente descubiertos.

El agua, procedente de un arroyo cercano, era conducida hasta el patio a través de una canalización subterránea doble localizada en la zona oriental, teniendo como finalidad servir para el regadío y, tal vez, también el desagüe de un posible jardín. Otra conducción fue descubierta en el sector septentrional de la villa.

\section{PALABRAS CLAVE:}

Aprovisionamiento de agua, arroyo, conducción hidráulica, establecimiento agrícola, villa romana.

\begin{abstract}
The hydraulic supply in this villa was distributed by different ceramics conductions. The water was conducted from a near stream to the courtyard by a double subterranean canalisation situated in the oriental side. These facilities had both an irrigating and, probably, a draining function, for the garden. Other conduction was found in the north side of the villa.
\end{abstract}

\section{KEY WORDS:}

Supplying of water, brook, hydraulic conduction, agricultural establishment, roman villa.

\footnotetext{
* Directora de la excavación. email: camengbueno@gmail.com
} 


\section{INTRODUCCIÓN}

En este trabajo abordamos diversos aspectos del uso del agua en el mundo romano, con particular incidencia en la villa de Puente de la Olmilla. Esta villa hispanorromana fue descubierta fortuitamente. En 1973 un agricultor encontró un mosaico mientras araba una parcela de tierra de labor a unos $3 \mathrm{~km}$ al Sur de la localidad de Albaladejo, a cuyo término municipal pertenece. Las coordenadas topográficas de este yacimiento son: $38^{\circ} 36^{\prime} 10^{\prime \prime} \mathrm{N} / 0^{\circ} 55^{\prime} 20^{\prime \prime} \mathrm{E}$, referidas a la hoja 840 del MTN a escala 1:50.000.

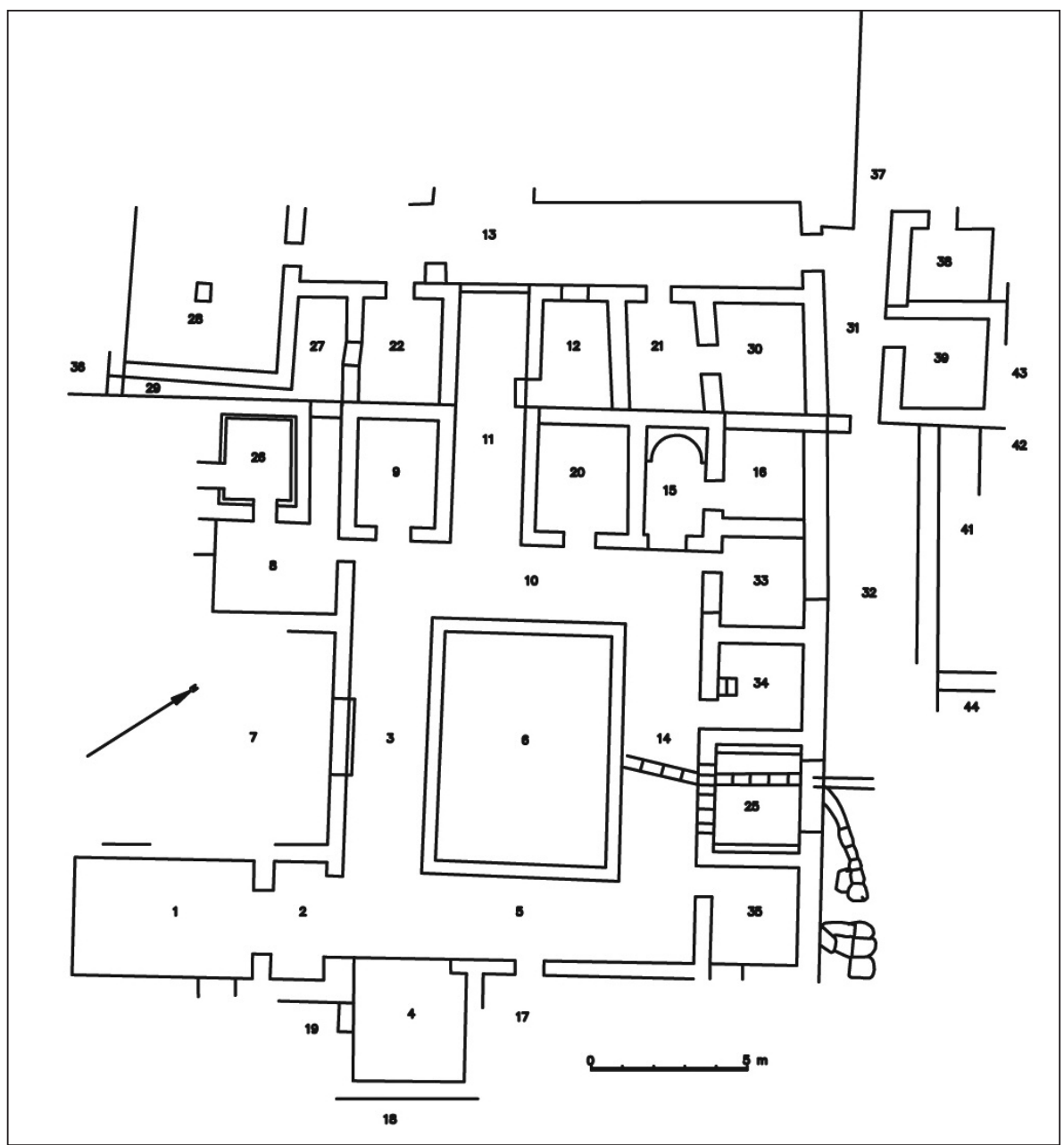

Fig. 1 Villa de PUENTE DE LA OLMILLA

Planta general 
Uso y disfrute del agua en la Villa Romana de Puente de La Olmilla...

Está enclavada en el centro de un valle muy llano que corresponde al sector más fértil del lugar. Como es habitual en la mayoría de los ámbitos geográficos de las villae, la tierra es propicia tanto para el cultivo (del que tenemos constancia arqueológica por algunos elementos de utillaje agrícola aparecidos, p. ej., dos hoces...), como para la práctica de la ganadería, mediante el aprovechamiento de sus pastos. Es un paraje muy ventilado, que recibe muchas horas de sol al año, circunstancia determinante en la organización de los espacios domésticos. Además, tiene una relativa abundancia de lluvias a causa de las favorables condiciones orográficas del terreno, por la proximidad de la Sierra de Alcaraz. Las necesidades

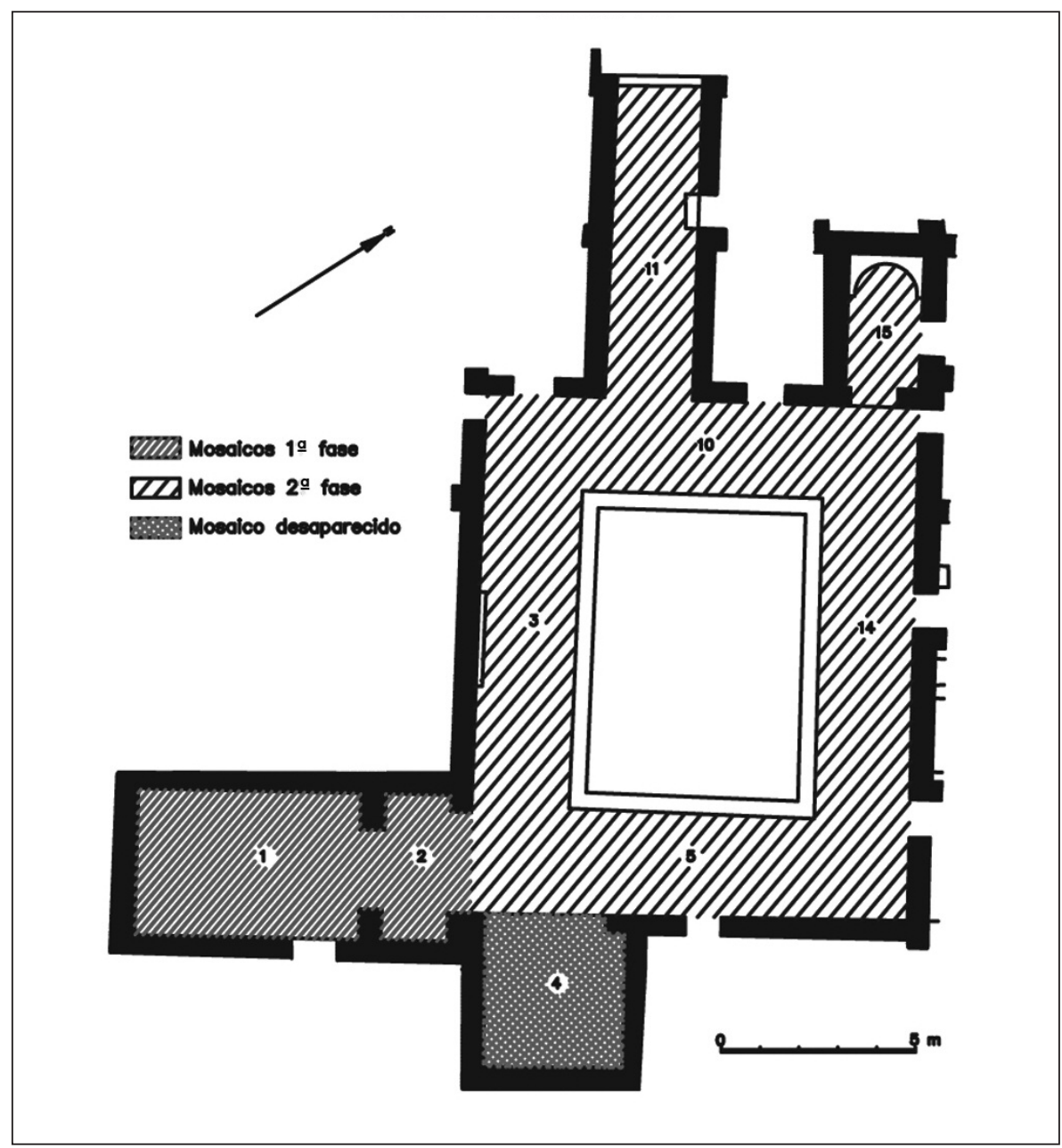

Villa de PUENTE DE LA OLMILLA

Área con mosaicos 
de agua estaban cubiertas por un pequeño cauce que discurre a unos $300 \mathrm{~m}$ al Norte: el Arroyo de la Bola.

Esta residencia rural es reflejo del alto nivel económico de sus dueños. A juzgar por los restos excavados, se trata de un establecimiento nacido de la mano de un possessor acomodado. Debió de ser un admirable modelo de bien vivir, que contaba con ciertos servicios como el agua corriente para hacer más confortable la vida del dominus y su familia. Tenía varios ambientes solados con mosaicos de buena calidad y sus paredes (no sólo las de las salas más nobles, sino también las de otras de diferente rango y las de los pasillos) estaban dotadas de un revestimiento interior de estuco pintado (PUIG OCHOA, M. R., 1979: 923-930), presentando diversas composiciones decorativas, con frecuencia de brillante policromía, en tonos rojo, amarillo, azul..., incluso con alternancia cromática en una misma superficie parietal.

Si, como creemos, fue pacíficamente abandonada (al no haber signos de destrucción violenta), sus habitantes se llevarían consigo los objetos y enseres más valiosos. Por ese motivo, tan sólo hemos recuperado unos cuantos ejemplares de esa selecta cultura material (pulseras, pendientes, fíbulas, agujas para el pelo, vidrios, una estatuilla de bronce...), prueba evidente de que sus refinados propietarios podían costearse la adquisición de productos suntuarios, como igualmente pudieron permitirse encargar, al menos, nueve mosaicos con un amplio repertorio de motivos geométricos, vegetales y figurados para embellecer los suelos de su casa de campo (cfr. PUIG OCHOA, M. R. y MONTANYA MALUQUER, R., 1975: 133143; BLÁZQUEZ MARTÍNEZ, J. M., 1982: 27-30; GARCÍA BUENO, C., 1994: 95116; 2001: 212-217). Combinadas con la ornamentación pictórica de los muros, estas creaciones artísticas, fechadas en el siglo IV, contribuyeron con su estilo barroco a aportarle una cierta prestancia y suntuosidad. Todo ello define la categoría del conjunto doméstico de Puente de la Olmilla, una villa de tipo señorial, a tenor de las estructuras descubiertas. En ella se han detectado dos niveles ocupacionales (y se han registrado diversas fases constructivas dentro del segundo): el más antiguo documentado se remonta a los siglos I-II d.C., etapa a la que se adscriben cronológicamente algunos escasos fragmentos cerámicos y varias piezas monetales. Buena parte del conjunto arquitectónico cuyos restos hemos sacado a la luz posiblemente se construyó ex novo durante el siglo IV o quizás se reconstruyó sobre la base de esa primera implantación altoimperial. Si aún quedaban indemnes algunas estructuras de la misma, después fueron camufladas por las bajoimperiales (GARCÍA BUENO, C., 1994: 95-116; 2000: 191-203).

\section{SUMINISTRO Y DISTRIBUCIÓN DEL AGUA}

Toda la región castellano-manchega se caracteriza por su bajo nivel pluviométrico, padeciendo grandes periodos de sequía, especialmente durante la estación estival. Albaladejo está ubicada en la denominada «España seca», donde tan sólo se recibe entre 600 y $350 / 300$ mm de agua anualmente. De ahí la gran im- 
Uso y disfrute del agua en la Villa Romana de Puente de La Olmilla...

portancia que tenía la disponibilidad de recursos hídricos para un complejo rústico como éste. El agua era uno de los principales condicionantes a la hora de elegir el emplazamiento de una villa, pues su provisión era imprescindible para el funcionamiento de la misma. Se convertía entonces en agua «utilitaria», al servir para el regadío de los campos, además de para el consumo humano. Era necesario, por tanto, evaluar la potencialidad de un territorio antes de decidir la ubicación de un asentamiento de este tipo. En este sentido, como es lógico, convenía disponer de acuíferos subterráneos o cursos fluviales cercanos como requisito previo para facilitar y garantizar el suministro, sin tener que recurrir a una complicada derivación de los mismos. Varrón (R.r. I, 2,2) destaca la necesidad de contar con la existencia de manantiales naturales o de corrientes nacidas en la montaña. En relación a esta premisa, al Este de Albaladejo se recorta en el horizonte la Sierra de Alcaraz, que alimenta con su escorrentía el sistema de drenaje local, destacando el río Guadalmena y el Arroyo de la Bola, también hay una fuente del mismo nombre y en la cuenca del río Villanueva existen varios balnearios, entre ellos, los Baños de Albaladejo, no muy lejos de los Baños del Relumbrar (CORCHADO SORIANO, M., 1974: 31-32). I. Hervás y Buendía (1890: 16) detalla que Albaladejo «se surte de aguas de la fuente del Santo, y otros manantiales no menos abundantes riegan y fertilizan su suelo».

En general, el caudal podía proceder tanto de las aguas superficiales como de las subterráneas, estas últimas, aprovechadas ya en la Antigüedad. Así sucedía posiblemente en Barcino, donde, según se cree, se explotó la riqueza freática de su subsuelo (MAYER, M. y RODÁ, I., 1977: 265-283). También Valentia se surtía directamente del mismo (ALBIACH DESCALS, R. et alii, 2009: 425).

La abundancia de agua debía de ser considerablemente mayor en época romana, sobre todo por la cuantía de la pluviosidad (cfr. BALIL ILLANA, A., 1977: 79, Fig. 1), al parecer, actualmente más baja que entonces, cuando había una más densa boscosidad (RODRÍGUEZ NEILA, F. J., 1988: 224), entre otras causas medioambientales. Sea como fuere, es sumamente difícil intentar reconstruir el estado de la red fluvial durante el periodo romano y hay que tener en cuenta las diversas modificaciones sufridas posteriormente, hasta nuestros días. En opinión de A. Schulten (1963, II: 45-100), los ríos de la Península Ibérica eran más caudalosos en la Antigüedad. J. Mangas (1981: 317), en cambio, sugiere que el régimen de lluvias y el cauce de los ríos no ha experimentado cambios notables desde entonces.

En algunas zonas ha variado la situación geomorfológica desde tiempos antiguos, como es el caso de Valentia y su entorno, donde el nivel freático ha sufrido un acusado descenso durante las últimas décadas debido a la sobreexplotación, un panorama muy diferente al que debía de haber bajo la dominación romana (ALBIACH DESCALS, R. et alii, 2009: 417).

Este factor físico es fundamental para entender la existencia de un enclave agrícola como es Puente de la Olmilla, no sólo por ser el agua un elemento indispensable para la vida de sus habitantes, sino también por su determinante incidencia en la actividad económica llevada a cabo en este lugar. 
En un mapa de distribución de las villae más significativas de Hispania (FERNÁNDEZ CASTRO, M. C., 1982: 42) observamos que los cursos fluviales aglutinaron en su entorno a la mayor parte de éstas, incluida la de Puente de la Olmilla. Esa evidente concentración responde a los motivos que acabamos de exponer.

Al investigar la explotación agrícola del valle del Betis, G. Bonsor (1899: 126268) defiende la tesis de que, por insignificantes que fueran, todos los manantiales fueron utilizados por los romanos. Desde luego, así sucedió en Puente de la Olmilla.

Por las inmediaciones del solar excavado fluye el citado Arroyo de la Bola. La villa está situada en su margen izquierda. Sin duda, las conducciones aquí descubiertas se alimentaban de esa corriente. Aunque desconocemos por ahora la localización del sitio concreto donde se producía la toma de agua, ésta se recibiría de dicho arroyo, ya que es la fuente acuífera más próxima y accesible. Dada la parcialidad de la intervención arqueológica realizada hasta el momento en este yacimiento (Fig. 1), carecemos de elementos suficientes para reconstruir el itinerario de traída de aguas, pues todavía no se ha encontrado la zona inicial de la que arranca el sistema de aprovisionamiento y únicamente hemos hallado el punto de destino de uno de los cordones hidráulicos: el patio (Fig. 1, n. 6), donde no hemos documentado la existencia de un impluvium, una cisterna o un piso, lo que, a nuestro entender, avala la teoría de que se trata del hortus de la casa (en relación al hortus como origen del jardín romano, destinado en un principio al cultivo de hortalizas para consumo propio, flores y plantas medicinales, cfr. SAN NICOLÁS PEDRAZ, P., 1997: 137; «la primitiva palabra para designar el jardín entre los romanos era hortus», como refiere BLÁZQUEZ MARTÍNEZ, J. M., 2001: 21). Probablemente este espacio abierto estaría adornado con zonas verdes y plantas decorativas (sobre los jardines romanos, cfr. la bibliografía compilada por SAN NICOLÁS PEDRAZ, P., 1997: 137-175). Blázquez (2001: 27-29) también nos proporciona algunos datos sobre la decoración de los jardines, como la frecuente presencia de fuentes en los horti de las villae (Plinio, Epist. V, 6, 36 y 40). El propósito de sembrar estos vergeles era introducir la naturaleza dentro de la casa de campo, creando así un lugar de esparcimiento, tan del gusto de los romanos. Por ello, no solían faltar espacios ajardinados en las grandes propiedades rurales tardorromanas, donde se podía reposar o pasear. El de Puente de la Olmilla se proveía de agua mediante una canalización subterránea que recorría el ala oriental (Fig. 1, n. 14, 25 y 32), seguramente en dirección al Arroyo de la Bola. No parece ser ésta la arteria principal de suministro hídrico de la villa, más bien nos inclinamos a pensar que su función estaba exclusivamente relacionada con el riego y/o drenaje de la zona ajardinada (posiblemente con ambos, si tuvo una doble funcionalidad, según las necesidades del momento, como creemos). De acuerdo con las evidencias arqueológicas, al no haber un estanque donde se pudiera almacenar el agua para regar (Paladio I, XXXIV, 2) o ni tan siquiera una simple pileta, sería necesario recoger el excedente de agua de lluvia caída a través del compluvium y conducirlo hasta algún otro lugar para evitar que el peristilo se inundara. La alineación que, tras bifurcarse, se dirige hacia el Sureste, bien pudo 
Uso y disfrute del agua en la Villa Romana de Puente de La Olmilla...

ser un canal secundario de desviación hacia el sector meridional de la vivienda e incluso quizás confluía con otras ramificaciones, distribuyendo el agua a distintos ámbitos; posiblemente estaba relacionada con el desagüe del líquido proveniente del patio, de hecho, en la habitación n. 19 apareció una cloaca con un albañal que discurría en sentido Este-Oeste, por debajo del muro medianero entre los departamentos $n .04$ y 19 , con la que podría estar unida. De esta manera se cerraría el circuito, dentro de un planificado reaprovechamiento del agua. Por otra parte, no se ha podido verificar si alguno de los dos brazos orientales estaba conectado con la canalización detectada en el frente septentrional de la villa, que se pierde al Norte, ya que la excavación no se ha extendido más allá en esa dirección, razón por la cual ignoramos si era un conducto de abastecimiento directamente procedente del cauce cercano. Tampoco podemos descartar que sirviera para avituallar de agua a otras dependencias septentrionales, aisladas o coordinadas de algún modo con la sección descubierta de la pars urbana (ya sea a través de algún pasillo, otro patio...), pues a varios metros de distancia de la misma, en el nivel superficial removido por las vertederas de los arados, hemos detectamos alineaciones de piedras pertenecientes a otros muros, ladrillos, tejas y diversos escombros, que corresponden a otras estancias. Cabe, por tanto, la posibilidad de que dicho conducto aportara agua a otros complejos constructivos, acaso diseminados por el entorno de la edificación señorial, ocupando un área independiente o unificados con ella, ya sea compartiendo el mismo volumen arquitectónico o bien en forma de otra ala. A falta de otros vestigios propiamente arqueológicos, sólo podemos movernos dentro del campo de la hipótesis y, pese a que no podemos llegar a conclusiones seguras al respecto, la coherencia de los datos analizados nos induce a pensar que ese tramo se prolonga por el Norte, avanzando en esa dirección, no obstante, nada más puede precisarse sobre su origen y fin, al hallarse ambos en el área no excavada.

\section{AGUA PARA EL CONSUMO DOMÉSTICO Y EL REGADÍO DEL AGER}

Una de las utilidades domésticas del agua en las residencias campestres romanas estaba vinculada a la extendida costumbre del baño. Por el momento, en el registro arqueológico sólo tenemos indicios de la existencia de unas instalaciones balnearias, según parece, segregadas del edificio principal o, al menos, diferenciadas del ámbito doméstico propiamente dicho, a tenor de las prospecciones realizadas en derredor de la vivienda dominal (PUIG OCHOA, M. R. y MONTANYA MALUQUER, R., 1978: 10), pero aún no sabemos cómo se producía la llegada y distribución interna del agua en este espacio termal y si alguno de los conductos exhumados estaba relacionado con él. En función de la ubicación del balneum se organizaría la infraestructura necesaria para surtirlo de agua y evacuar ésta una vez usada. De los exiguos datos proporcionados por ambos autores, se deduce que no estaba demasiado lejos del pequeño torrente antes mencionado. De hecho, carecería de lógica tener que construir una red hidráulica muy extensa, pudiendo 
emplazar las salas termales en las proximidades del mismo, con lo que su recorrido sería menor.

Al estudiar los balnea domésticos rurales hispanorromanos, V. García-Entero (2005: 870) observa que éstos solían estar incluidos en el conjunto arquitectónico de la casa, pero «formando unidades constructivas propias e independientes», lo que, a su entender, se debía «no sólo a cuestiones de orientación, sino también a la propia disponibilidad de agua», en función de la cual se situaban cerca de manantiales naturales, acuíferos subterráneos o cursos fluviales. Asimismo, señala que, salvo casos excepcionales, su abastecimiento hídrico no dependía de la ejecución de grandes obras (acueductos...), sino de «soluciones puntuales y concretas» (GARCÍA-ENTERO, V., 2005: 854). En este sentido, la villa de Puente de la Olmilla es bastante modesta, comparada con otras como la de Monroy (Cáceres), donde se hizo un pequeño embalse (CERRILLO MARTÍN, E. et alii, 1986: 122), o la de San Cucufate, cuyo propietario construyó un complejo sistema hidráulico, incluyendo un acueducto (ALARÇAO, J., ETIENNE, R. y MAYET, F., 1990), al igual que en La Cocosa, Badajoz, (SERRA RÁFOLS, J. de C., 1952: 95). En la publicación que estamos citando reiteradamente, la autora (GARCÍA-ENTERO, V., 2005: 867-868 y 870) concluye que las dependencias termales «estuvieron presentes en la inmensa mayoría de las villae erigidas a partir del siglo I d.C.» en Hispania y alude a la generalización de los recintos de baño en el mundo rural, por muy humilde que fuera el establecimiento (acerca de los «cuartos de baño en las villas», cfr. MALISSARD, A., 1996: 105-106).

Una dificultad de primer orden es la parquedad de noticias proporcionadas por los autores clásicos sobre la gestión y el uso de los recursos hídricos en Hispania, pero podemos imaginar que fue uno de los primeros problemas que los romanos se plantearon a la hora de elegir el lugar idóneo para la implantación de cualquier tipo de hábitat, por ese motivo seleccionaron cuidadosamente el paraje donde se iba a edificar éste, un fértil valle que, además de tener buenas tierras para el cultivo, contaba con un suministro acuífero. La traída de agua debía ser una labor previa a la construcción de cualquier villa, según aconseja Varrón (R.r. I, 11,2). Igualmente, Puente de la Olmilla se adecua a otra de las prescripciones de estos tratadistas romanos: la conveniencia de erigirla en un sitio propicio como es en el aterrazamiento de un curso fluvial.

Los Agrónomos latinos ponen el mayor énfasis en resaltar que la productividad de un terreno rústico depende en buena medida de su contingente de agua y recomiendan que la quinta disponga de un buen depósito o esté localizada cerca de una abundante fuente de agua, un río... (Catón, De Agr. I, 1,3). Columela (De r.r. I, 2,3 y 5,1 y 2) hace hincapié en la necesidad primordial de ese elemento para cualquier villa, omnipresente en todas ellas, e indica que el agua potable debe canalizarse mediante cañerías de barro a una cisterna: «debe de haber una fuente que siempre tenga agua, bien nazca dentro de la villa, bien se introduzca de fuera..., si no hubiera agua corriente se construirán cisternas para los hombres, charcas para los ganados», apostillando a continuación: «mas para templar los calores del 
Uso y disfrute del agua en la Villa Romana de Puente de La Olmilla...

estío y hacer que un sitio sea ameno contribuyen muchísimo los arroyos» (Columela, De r.r. I, 5,4).

Considerando la dureza de la sequía estival en este territorio, caracterizado por las escasas precipitaciones, es factible que Puente de la Olmilla estuviera provista de algún receptáculo de almacenamiento del agua pluvial, ya que el vecino arroyo ocasionalmente podía ser víctima del estiaje, provocando un bajo caudal y dejando de surtir temporalmente a la villa, en mayor o menor medida. Recoger y conservar el agua de lluvia sería vital entonces, como aportación suplementaria, sobre todo durante la estación seca.

Es imposible calcular el volumen del caudal de líquido conducido desde el arroyo hasta esta villa, pero debió de ser considerable para alimentar la red de captación de aguas desplegada en la misma, con el fin de hacer posible el aprovechamiento de esa corriente, proporcionando el agua suficiente para el funcionamiento de la casa. En cuanto al regadío del ager, únicamente podemos suponer que quizás también se surtiría de ella mediante una más amplia instalación hidráulica, aunque en el estado actual de las investigaciones carecemos de datos para confirmarlo (por ahora, insistimos, tan sólo ha sido parcialmente descubierta). El agua para el riego de la finca pudo ser encauzada mediante canales de obra, p. ej., realizados con material latericio o con imbrices, que han aparecido en abundancia por los alrededores. La canalización de agua, utilizando en unas ocasiones ladrillos y, en otras, tejas, está bien documentada en numerosos enclaves romanos, como el vicus de Bedriacum (PASSI PITCHER, L., 1996: 65 y 71, Fig. 32) o la villa cordobesa de El Ruedo (VAQUERIZO GIL, D. y NOGUERA CELDRÁN, J. M., 1997: 2628,37 , donde una gran cisterna serviría al riego, o bien se recurrió a otros sistemas de irrigación, tales como pozos. Se han encontrado varios junto a algunas villae, por poner sólo algún ejemplo a modo ilustrativo, en la de Pedrosa de la Vega (Palencia), en la de Santa Cruz (Baños de Valdearados, Burgos) y en la de Monroy (Cáceres), donde también se excavó una fuente, e incluso están representados en la musivaria romana, como el pavimento itálico de Oderzo (BERTACCHI, 1983: 6573, Láms. XLVI y CCXXXI; LÓPEZ MONTEAGUDO, 2006-2007: 197; 2010: 240, Fig. 6). Al no haber comprobación arqueológica suficiente en la de Puente de la Olmilla, formulamos esta hipótesis de trabajo como una posibilidad a tener en cuenta. Evidentemente, el agua tendría un papel determinante en la explotación de los extensos terrenos cultivables que entonces, como ahora, rodeaban la villa y, en consecuencia, parece lógico pensar que se realizara algún trabajo hidráulico relacionado con esta cuestión.

Blázquez $(1977,160)$ nos transmite algunas noticias sobre la existencia de regadíos en la Península Ibérica durante la época romana, aun siendo escasas las menciones recogidas en la legislación y la epigrafía hispanas. En su opinión, el método no debía de ser muy diferente al descrito por Romanelli (1970: 259) para el Norte de África, donde se construían cisternas para almacenar el agua de lluvia, se abría pozos, se encauzaba las aguas, asimismo, había depósitos de reserva, utilizados para regar los campos de labor (sobre el regadío, cfr. SERRA RÁFOLS, J. de C., 1947: 455-456, 460 y 463-464; GORGES, J.-G.,1979: 404; RODRÍGUEZ 
NEILA, F. J., 1988: 225; LACORT NAVARRO, P. J., 1989: 361-404; específicamente sobre la agricultura de regadío durante la Antigüedad tardía en el Sur peninsular, cfr. VENTURA, F. S., 1989: 405).

Todavía subsisten en la actualidad algunos conductos de plomo que suministraban el agua a diversos establecimientos rústicos romanos, como el lusitano de San Cucufate, tanto para el regadío de los horti como para abastecer los diferentes edificios de ese complejo agrícola, cuya cronología abarca desde el siglo II al IV d.C. (ALARÇAO, J., ETIENNE, R. y MAYET, F., 1990: 188 y 193) e igualmente en muchos otros lugares del Imperio sirvieron para irrigar los fundi (GORGES, J.-G., 1992-1993: 261).

Pese a que la agricultura de secano era el sistema dominante en buena parte del territorio peninsular durante el periodo romano, existen datos alusivos al regadío de la vid (SÁEZ FERNÁNDEZ, P., 1987: 33). Columela (De r.r. V, 12) habla de cierto tipo de vides de la Bética (capitatae) que se regaban. También Justino, en su epítome a Trogo Pompeyo (XLIV, 1,7), comenta que algunos ríos hispanos se utilizaban para regar viñedos. Por último, Plinio (N.H. XVII, 248) relata que la vendimia se realizaba en Hispania en un suelo encharcado de agua de riego, pero es poco probable que estas observaciones puedan aplicarse a la zona objeto de nuestro estudio. Lo que sí podríamos relacionar con ésta es un texto de Apiano (Iber, 64) sobre la existencia de plantaciones de olivo en la Meseta Sur.

Tradicionalmente las tierras de Albaladejo se han dedicado al cultivo cerealístico y oleícola -cultivos de secano-, cuya explotación ha continuado activa hasta nuestros días, complementado por el regadío, cuyo aporte de agua se consigue a base de pozos, que da cosechas de patatas, maíz y diversos productos de huerta. En época tardorromana las villae como ésta de Puente de la Olmilla, donde primaría la autosuficiencia, aparte de procurar garantizarse la provisión de grano, vino y aceite mediante la producción obtenida en la finca, generalmente se surtían de productos hortícolas y frutales propios, que requerirían ser regados con cierta frecuencia. Con todo, el regadío probablemente debió de ocupar aquí un lugar secundario dentro de los cultivos existentes.

A. Schulten (1963, II: 180) rastrea las fuentes literarias y epigráficas buscando datos sobre la agricultura practicada en Hispania durante la Antigüedad romana y argumenta que ya en esa etapa histórica «la Cordillera Carpetovetónica formaba una frontera climática muy precisa entre Castilla la Nueva y Castilla la Vieja», asimismo, valora con ciertas reservas una cita de Apiano (Iber. 64) donde se califica de «afortunado» al territorio que él identifica con Castilla la Nueva, relativizando esa apreciación del historiador griego, sólo aceptable, a juicio del investigador alemán, si se compara con la crudeza climatológica de Castilla la Vieja: «Después de las guerras en la Meseta celtibérica los ejércitos romanos invernaban en Andalucía o Castilla la Nueva. Tenemos testimonio de esto para Castilla la Nueva en el año 135 (Apiano, Iber. 83)». Del mismo modo, matiza un pasaje de Justino (44, 1) donde se describe Hispania con rasgos ideales genéricos, alusivos a su fertilidad: «No está desecada como África por un sol ardiente (...), sino que goza de una 
Uso y disfrute del agua en la Villa Romana de Puente de La Olmilla...

posición intermedia con calores mesurados y lluvias oportunas y benéficas, así que es rica en toda clase de frutos. (...) Aquí las corrientes de agua no son torrenciales y rápidas, de forma que produzcan daños, sino suaves y apropiadas para el riego de las vides y los campos... La salubridad del clima es igual en toda España». Schulten (1963, II: 183) asume que estos elogios se refieren únicamente al Suroeste peninsular, pues la Meseta posee un clima extremado con bruscos cambios de calor y frío, perteneciendo a una de las tres zonas climáticas de Iberia diferenciadas por Estrabón (III, 3), concretamente, la que «se compone de montañas, bosques y llanuras de suelo pobre con poco agua».

\section{AGUA UTILITARIA Y ORNAMENTAL}

En definitiva, el agua desempeñaba un papel privilegiado en toda la extensión del Imperio, no sólo como elemento vital, sino por su relación con prácticas de higiene, recreativas, etc. Tenemos noticias de su uso con las más diversas finalidades, pues para los romanos no sólo tenía un carácter o valor funcional, sino que, por el efecto estético de los juegos de aguas, de una plástica perecedera, también servía para crear artificios ornamentales y espectáculos (alimentando fuentes o formando parte de la escenografía y decoración de algunos teatros, ninfeos monumentales, etc., al respecto, cfr. BALIL ILLANA, A., 1977: 77-89; LOZA AZUAGA, M. I., 1994: 263-283; MALISSARD, A., 1996: 73-100, 138-139; BLÁZQUEZ MARTÍNEZ, J. M., 2001: 28, 34-35). Malissard vincula el agua ornamental a la civilización romana, como señal de lujo, refinamiento y progreso. Evoca el pequeño viridarium de la Casa de los Vetii, donde todavía se ven tuberías de plomo destinadas al riego de plantas y árboles. Por influjo de los cambios culturales y de las modas «el huertecillo, que antaño se extendía detrás de un sombrío atrio (...), no era ya más que un vago recuerdo; los nuevos jardines, aunque heredados de una larga y antigua tradición, se beneficiaban a su vez de la abundancia propia de la época» (MALISSARD, A., 1996: 77-78), donde el agua servía también para organizarlos, embellecerlos y darles exuberancia, rivalizando para ello los jardineros con los arquitectos. Se acondicionaba así jardines y paseos en el centro de las mansiones o alrededor de ellas. Al ofrecernos una idílica imagen del esplendor de sus jardines, Plinio el Joven (Cartas, 5, 6, 40) menciona «arroyuelos conducidos por tuberías» («inducti fistulis rivi») y Marcial (XII, 31, 2) dice que los suyos son refrescados por «un río canalizado» («flumen ductile»).

En el patio bordeado por un peristilo de la llamada Casa de los juegos de agua de Conimbriga había más de cuatrocientos surtidores y un estanque central, comunicado con las letrinas mediante un canalillo de evacuación, que se limpiaban al vaciar la piscina (BLÁZQUEZ MARTÍNEZ, J. M., 2001: 34). Al igual que en la villa de Albaladejo, había un espacio ajardinado en el interior de su peristilo. Lo mismo sucedía en muchas otras villae, como la de El Saucedo (Talavera la Nueva, Toledo), donde se constata la existencia de un peristilo-jardín. En éste, el componente central es una fuente ornamental (CASTELO RUANO, R. et alii, 2006: 176). En el triclinium de la villa de El Ruedo (Almedinilla, Córdoba), el agua era un elemento de 
enorme importancia y se buscó dar a los comensales una efectista impresión de estar junto a un riachuelo o «una pequeña isla (...), que, de alguna manera, se sumaría a esos conceptos de paesaggio culturale y giardino mitologico que tan característicos fueron de algunos de estos ambientes", siguiendo modelos enraizados en el espíritu cultural helenístico, vigente en las clases altas de la sociedad tardorromana (VAQUERIZO GIL, D. y NOGUERA CELDRÁN, J. M., 1997: 71, Lám. 22, A). Son numerosos los vestigios arqueológicos de conducciones de agua en las villae romanas y en particular en las hispanas (FERNÁNDEZ CASTRO, M. C., 1982: Figs. 95-96).

En el mosaico de los Peces de la villa de la Vega Baja de Toledo, datado a comienzos del siglo IV (BLÁZQUEZ MARTíNEZ, J. M., 1982: 38, Láms. 20-22; GORGES, J.-G., 1986: 183-187, Lám. I, Fig. 1; Láms. II-III, Fig. 1) se representan dos viIlae, una de ellas con una zona ajardinada dentro de un peristilo, en cuyo centro se aprecia unas líneas que han sido identificadas como canalizaciones hidráulicas. «Este mosaico constituye un ejemplo unicum de la figuración de la irrigación del jardín mediante canales» (SAN NICOLÁS PEDRAZ, P., 1997: 147).

Un amplio elenco de seres mitológicos y de figuras alegóricas del mundo acuático aparece representado en diversos mosaicos hispanorromanos. Suelen tener «un significado especial por el valor profiláctico del agua como generadora de fertilidad y prosperidad» (SAN NICOLÁS PEDRAZ, P., 2004-2005: 302).

En un pavimento musivo del siglo IV descubierto en Mérida, Opora es una personificación alegórica de una fuente: el agua que brota de un kantharos, del que mana un río, riega los campos, favoreciendo la proliferación de la vida vegetal y animal; de este modo se recalca la riqueza y abundancia que lleva aparejadas. A juicio de G. López Monteagudo (2010: 237-240, Figs. 1-4), un cesto con frutos simboliza esta misma idea, al igual que la guirnalda de flores (cfr. LÓPEZ MONTEAGUDO, 2006-2007: 188, 192-194, 196) y todo el cuadro en sí, con rebaños de animales pastando cerca de un torrente, nos ofrece una imagen realista de la vida cotidiana en el medio rural, asociada a las villae. Muy similar es el panorama plasmado en el mosaico itálico de Oderzo (BERTACCHI, 1983: 65-73, Láms. XLVI y CCXXXI; LÓPEZ MONTEAGUDO, 2006-2007: 197; 2010: 240, Fig. 6), donde se contempla una escena campestre con una villa amurallada, ovejas pastando, venationes, etc., al igual que en varios mosaicos norteafricanos y orientales (recopilados por LÓPEZ MONTEAGUDO, 2010: 240 nota 16), reflejando todos ellos «la realidad social del momento (...), de su riqueza agrícola y ganadera (...) y siempre con el agua como factor determinante de esa riqueza». La musivaria nos ofrece vívidamente diversas estampas de un mundo bucólico, en contacto con la naturaleza, y en este panorama el agua está muy presente.

Con el fin de proporcionar la humedad necesaria a las plantas de los jardines se solía instalar fuentes, de las que había varios tipos (SAN NICOLÁS PEDRAZ, P., 1997: 138-157, estudia tres de ellos representados en diversos mosaicos pavimentales y en pinturas pompeyanas). Cuando resalta el papel del agua como recreo, A. Balil (1977: 87) comenta que difícilmente se encuentra en la Península lbé- 
Uso y disfrute del agua en la Villa Romana de Puente de La Olmilla...

rica casas romanas, en especial si son campestres, donde «el agua y su sortilegio no haya sido motivo de goce» gracias a la presencia de fontanas, piletas, etc., con cascadas, surtidores y vertederos, para crear frescor ambiente y contribuir a un sentimiento de sosiego. Aunque no hay rastro de una piscina o una fuente en el patio de la villa de Puente de la Olmilla, un conducto cerámico le aportaba agua y seguramente el segundo ramal del mismo sería el encargado de evacuar la sobrante a la referida cloaca o al exterior (vid. supra). Como ya expusimos, cabe interpretarlo como indicio de la existencia de un viridarium u hortus, pero no prueba si, además, nutría y desaguaba una fuente ornamental (el hallazgo de un fragmento de mármol es insuficiente para sustentarlo). Únicamente podemos planteárnoslo como hipótesis, sin descartar tampoco la posibilidad de que dicho fragmento presumiblemente pudiera ser testimonio de un revestimiento con lajas de mármol en alguna zona puntual. Al hilo de esta cuestión, conviene recordar que en la villa de El Saucedo apareció una plaqueta sumidero de mármol blanco, comunicada con un canal de desagüe (CASTELO RUANO, R. et alii, 2006: 185).

\section{LA CONDUCCIÓN DEL AGUA}

Los lugares donde se necesitaba el agua se alimentaban, pues, a base de canalizaciones más o menos complejas. Se recogía de ríos y manantiales (en este caso concreto, un arroyo) mediante redes hidráulicas, transportándola así hasta los puntos de consumo. Como frecuentemente se debía salvar cierta distancia entre la zona de origen y la de destino, resolvieron encauzar el líquido en conductos más o menos largos, que se iban ramificando. En Puente de la Olmilla se recurrió a este sistema para solucionar el problema de proveer a las necesidades cotidianas de agua, dado que no planteaba grandes dificultades técnicas a los constructores de esta vivienda. Lo que sí tendría una mayor complejidad sería la edificación del balneum. Por lo general, el elaborado esquema de estos conjuntos termales implicaba una cuidadosa planificación para conseguir su buen funcionamiento. Para reconstruir teóricamente el circuito del agua que abastecía aquí tanto al sector balneario como al resto de la casa hemos de pensar que, desde el pequeño torrente localizado en las proximidades del complejo rural, este elemento hídrico sería tal vez conducido hasta algún gran depósito, donde mediante tracción manual o animal (e incluso utilizando ciertos mecanismos, p. ej., en algunas villae se empleó un sistema de norias, cfr. GARCÍA-ENTERO, 2005: 870), se elevaría el agua hacia las canalizaciones que lo repartirían por las diversas instalaciones de la pars urbana y quizás también de la rustica, con destino a las faenas agrícolas. En la musivaria romana se refleja algunos aspectos relacionados con el agua, tales como distintos métodos de extracción (desde el más elemental, consistente en la cuerda y el cubo, hasta el uso de la garrucha, la pértiga de balancín, la rueda hidráulica...), ingenios mecánicos para elevarla (p. ej., la noria), entre otros (LÓPEZ MONTEAGUDO, G., 1997: 453-466). También las fuentes escritas hacen alusión a algunos de ellos, como Vitrubio (X, 9, 21-23), que describe tres tipos de norias. 
Serra Ráfols (1947: 462-463) pone de manifiesto que los romanos llevaban a cabo estos trabajos con la perfección técnica y los vastos conocimientos que tenían de hidrología, demostrando su gran pericia y el control adquirido sobre este recurso, p. ej., en la villa de Las Tomas (Badajoz). La mayoría de estas técnicas procedían de Oriente y Grecia, pero la ingeniería romana las perfeccionó, aportando diferentes innovaciones, lo que supuso un gran progreso tecnológico. Llegaron a controlar todo el proceso relacionado con el agua: la buscaban, la extraían, la encauzaban, la almacenaban cuando era preciso conservarla, la distribuían y la administraban. Poseían, por tanto, una desarrollada técnica constructiva que les permitía conducir artificialmente el agua incluso en condiciones topográficas adversas (como, p. ej., una agreste orografía) y eran capaces hasta de desviar los ríos de su cauce natural mediante canales. Todos estos logros fueron fundamentales para garantizar su avituallamiento, dirigiendo a ese objetivo un notable esfuerzo colectivo, pues un pueblo tan emprendedor, pragmático y organizador como el romano no podía limitarse a la idea de esperar a que les llegara espontáneamente este valioso líquido literalmente «llovido del cielo», por lo que recurrieron a los más diversos medios con tal fin. A un nivel más modesto, algunos de estos elementos (concretamente, el procedimiento de acercar el agua a la villa mediante canalizaciones) forman parte de la infraestructura básica del asentamiento que estudiamos.

Vitrubio (De Architectura VIII, 7) menciona que la conducción de aguas se puede hacer de tres maneras: por zanjas mediante obras de albañilería, con tubuli de terracota ${ }^{1}$ o con fistulae de plomo. Las de bronce eran escasas entre los romanos, no obstante, hay constancia de ellas en algunas lujosas villae ${ }^{2}$ y en las fuentes de algunas ciudades, como la de Cástulo (CIL II, 3280). En ocasiones coexistían los dos sistemas de circulación libre por canal de mampostería (canalis structilis) y la circulación bajo presión, empleando piezas tubulares de arcilla o de plomo (Vitr., De Architectura VIII, 6,1; cfr. DAREMBERG, CH.- SAGLIO- POTTIER, EDM, 1969, I/C: 1589.II; V: 528). En esta villa de Albaladejo únicamente han aparecido canalizaciones formadas por tejas, pero no podemos descartar que hubiera tuberías de plomo, pues su hallazgo en las excavaciones suele ser escaso, al haber sido con frecuencia objeto de un saqueo sistemático desde la Antigüedad «por las posibilidades de reciclaje que ofrecían» (RUIZ ACEVEDO, J. M. y DELGADO BÉJAR, F., 1991: 52). Este expolio está atestiguado en numerosos edificios romanos, como las termas de Cercadilla, en Córdoba (HIDALGO PRIETO, R., 1996: 198).

1 A las piezas de cerámica, madera o piedra se les denominaba «tubuli Fictiles», mientras que se llamaba «fistulae» a las de metal, sobre todo a las de plomo, mucho más abundantes que las de bronce (sobre este particular, cfr. BELTRÁN, 1977: 121 y la bibliografía específica que éste recoge relativa a los tubuli). Vitrubio detalla en el capítulo VIII de su obra De Architectura los distintos sistemas de captación y canalización del agua para proveer su abastecimiento. «Ductus autem aquae fiunt generibus tribus: riuis per canales structiles, aut fistulis plumbeis, seu tubulis fictilibus. Quorum hae sunt rationes. Si canalibus, ut structura fiat quam solidissima, solumque riui libramenta habeat fastigata ne minus in centenos pedes semipede eaeque structurae confornicentur, ut minime sol aquam tangat» (Vitr., De Architectura VIII, 6).

2 Entre otros casos, en la villa de Boscoreale, conocida como «la Pisanella», apareció in situ, sobre el hogar, una caldera cilíndrica de plomo con fondo de cobre, que tenía tubos con grifos de bronce, mediante los que se conectaba con un depósito (ADAM, J. P., 1984: 294). 
Uso y disfrute del agua en la Villa Romana de Puente de La Olmilla...

Aparte del hecho de que las fistulae plumbeae tenían más posibilidades de ser sustraídas por el valor de su materia prima (FERNÁNDEZ CASADO, C., 1983: 299; RUIZ ACEVEDO, J. M. y DELGADO BÉJAR, F., 1992: 44), la ventaja de los tubos de barro sobre los de plomo es que su fabricación es más barata y son más fáciles de reponer si se deterioran. Asimismo, una idea muy extendida entre los romanos era que los de arcilla conservan mejor la pureza del agua, pues el contacto del plomo la volvería insalubre, como asegura Vitrubio (De Architectura VIII, 7): «el agua es más sana cuando viene por tubuli que transmitida por fistulae; la razón está en que el plomo la vicia (...), del plomo nace la cerusa, que es perjudicial para el cuerpo humano».

A su vez, Plinio (N.H. XXXI, 57) declara: «no hay nada mejor que las tuberías de barro». Según explica Vitrubio (De Architectura VIII, 6-11), «Las conducciones por tubos cerámicos tienen además estas ventajas: en primer lugar, en el tipo de trabajo, porque si hubiera una avería, cualquiera puede repararla. También porque el agua que viene por estos tubos es mucho más sana que la que lo hace por tubos de plomo, desde el momento en que por el plomo parece que se contamina, ya que de él sale el albayalde, que se dice que es dañino para las personas. Así, al igual que lo que sale de él es nocivo, no hay duda de que él mismo tampoco es saludable. Podemos poner como ejemplo a los plomeros, que pierden el color del cuerpo y se ponen pálidos. Pues para fundir el plomo hay que insuflar aire y vapor que emana, penetra en los cuerpos y los consume hasta agotar las cualidades de su sangre. Por ello me parece que no se ha de conducir el agua por tuberías de plomo, si queremos que sea de buena calidad. Que cuando viene por tuberías de barro tiene mejor sabor queda de manifiesto a la hora de comer a diario, pues aunque en la mesa se hayan puesto vajillas de plata, todos usan vasos de barro porque no afectan al sabor».

En opinión de A. Beltrán (1975: 1.051), las fistulae de plomo eran más comunes que las piezas de arcilla, pero, teniendo en cuenta que no sólo era más fácil hacer una teja o un tubo de cerámica ${ }^{3}$ que uno de plomo, al no requerir su manufactura un operario muy especializado (quilibet it potest reficere), sino que también era menos costoso, seguramente los de barro fueron más asequibles y sencillos de conseguir.

Además de los autores latinos, como Vitrubio (De Architectura VIII, 7), Frontino (De aquaed. XXV) o Plinio (N.H. XXXI, 57), entre otros, que hacen referencia a las cañerías de terracota utilizadas para conducir el agua -al margen de los otros sis-

${ }^{3}$ En algunos epígrafes se hace referencia a esclavos municipales que fabricaban tuberías de cerámica (HALKIN, L., 1965: 174). También eran producidas por hombres libres asociados en colegios profesionales, como los de Venusia: los Aquari (CIL IX, 460). Por su parte, la manufactura de fistulae requería una mano de obra especializada (RUIZ ACEVEDO, J. M. y DELGADO BÉJAR, F., 1991: 51; MALISSARD, A., 1996: 203-206). Repartidos por las provincias del Imperio había talleres artesanos que fabricaban tubos de plomo, un metal muy abundante en esta zona de la Península lbérica, la actual provincia de Ciudad Real, gran productora de mineral de galena, pero a raíz de las transformaciones económicas acaecidas durante la época tardía, el panorama debió de cambiar sustancialmente también en los sectores de la minería y las industrias artesanales, sobre todo en áreas rurales como la estudiada. 
temas de acometida ${ }^{4}$ citados previamente-, contamos con numerosos testimonios arqueológicos repartidos por todo el orbe romano.

Al decir de varios especialistas, se emplearon anteriormente a las de plomo (FORBES, R. J., 1964, I: 153; LACORT NAVARRO, P. J., 1989: 384). La invención de tuberías de barro cocido parece remontarse al periodo minoico, habiendo sido utilizadas también en las antiguas civilizaciones del Indo, en Mesopotamia, en Etruria, etc. En territorio peninsular están documentadas desde época ibérica, así, en el poblado prerromano del Cerro de la Cruz (Almedinilla, Córdoba), abandonado a mediados del siglo II a.C., se descubrieron dos cisternas, en una de las cuales había dos tubos de cerámica con los extremos de diferente grosor para poder acoplarlos entre sí y en la otra se halló una cubeta de plomo junto a un conducto de tubos de arcilla (VAQUERIZO GIL, D., 1990: 285-286 y 288).

Se conservan restos de tubuli en innumerables lugares, entre los que se cuentan las provincias romanas de Bretaña, Mesia y Tracia, igualmente, en Macedonia (FERNÁNDEZ CASADO, C., 1983: 355, 357-363, 373-377), en Éfeso (ADAM, J. P., 1984: 276-277), en Antioquía (LEVI, D., 1947, I: 88, Fig. 33), en Ginebra, Limoges y Estrasburgo (MALISSARD, A., 1996: 199) o, por citar algún ejemplo de la Península Itálica, en Pompeya, en Ostia (ADAM, J. P., 1984: 285 y 289; PASCOLINI, A., 1985: 79-81), en Bedriacum (PASSI PITCHER, L., 1996: 70-72) y, para concluir esta lista rápida, en multitud de yacimientos dentro de nuestras fronteras, como La Loba (Córdoba), donde se encauzaba el agua tanto mediante tubos cerámicos como con bocas y cuellos de ánforas «enchufados unos en otros» (BLÁZQUEZ MARTÍNEZ, J. M., 1981: 11; 1982-83: 28-39) o el poblado de Valderrepisa, situado en Fuencaliente (Ciudad Real), que tenía una amplia red hidráulica compuesta por caños de barro ensamblados cuyas uniones estaban selladas con un sólido mortero de cal para evitar la filtración del agua y donde se controlaba la distribución de ésta mediante una arqueta de plomo (FERNÁNDEZ RODRÍGUEZ, M. y GARCÍA BUENO, C., 1993: 25-50; 1994: 195-210; 1997: 55-62; GARCÍA BUENO, C. y FERNÁNDEZ RODRÍGUEZ, M., 1995: 24-31; 1997: 193-198). En Saldaña se descubrió un posible desagüe formado por cilindros de cerámica (CORTES, J., 1975: 200). También se han encontraron tubuli pertenecientes al acueducto romano de León (SANTANDER, M., 1970: 472). En el acueducto de Alcanadre-Losada (Navarra) hay abundantes tuberías de terracota y un aliviadero para regular el caudal hídrico (MEZQUÍRIZ IRUJO, M. A., 1979: 139-145). En Almuñécar ha pervivido un sifón con tubos cerámicos, asociado al acueducto (FERNÁNDEZ CASADO, C., 1949: 313-333) y

4 Construcciones de ingeniería hidráulica abundan en todo el Imperio romano. En Hispania existen numerosas obras de este tipo para abastecer núcleos urbanos (entre otros, cfr. MAYER, M. y RODÁ, I., 1977: 265-283; SÁENZ RIDRUEJO, F., 1977: 351-358; SÁNCHEZ ABAL, J. L., 1977: 359-366; MEZQUÍRIZ IRUJO, M. A. y UNZU URMENETA, M., 1985: 237-254; STYLOW, A.U., 1986: 285-311; LACORT NAVARRO, P. J., 1989: 376; OREJAS SACO DEL VALLE, A., 1989: 45-67; RUIZ ACEVEDO, J. M. y DELGADO BÉJAR, F., 1991; MONTAÑÉS CABALLERO, S., 1993: 32-39; ARENILLAS PARRA, M. et alii, 2009) y diversas villae rusticae (GORGES, J.-G., 1979; PUERTAS TRICAS, R., 1986-87: 145-148; LACORT NAVARRO, P.J., 1989: 361-404, etc.). 
Uso y disfrute del agua en la Villa Romana de Puente de La Olmilla...

en las termas de Los Bañales (Uncastillo, Zaragoza) apareció un buen número de ellos, dispuestos para ser acoplados entre sí, sin codos (BELTRÁN MARTíNEZ, A., 1975: 1.051). Además, están documentados en gran cantidad de villae, como la de El Ruedo (Almedinilla, Córdoba), en cuyo peristilo hay un estanque servido por una canalización cerámica (VAQUERIZO GIL, D. y NOGUERA CELDRÁN, J. M., 1997: 69-70, Lám. 20, B), en Las Tamujas de Malpica de Tajo (PALOMEQUE TORRES, A., 1955: 311, Fig. 13; 1963: 198), en Cuevas de Soria (MARINÉ ISIDRO, M., 1984: 406), en La Olmeda (Palencia), en la bodega leridana de Balaguer (DÍEZ-CORONEL y MONTULL, L., 1968: 781), en la villa talaverana de El Saucedo (CASTELO RUANO, R. et alii, 1997: 66, 73-74), con diversos tipos de tubos: piezas cerámicas de forma troncocónica, con reborde anular, que presentan similitudes con algunos ejemplares de las termas de Popilio, en el Tosal de Manises (FIGUERAS PACHECO, F., 1971), y en el complejo vilicario de Daragoleja (Granada) se produjo el hallazgo de tubi laterii (FERNÁNDEZ CASTRO, 1978: 327)...

Malissard (1996: 200) señala que los de arcilla se usaron mayoritariamente «para el riego de jardines, la instalación de cisternas o la conducción de agua sucia», idea secundada por Lacort (1989: 384), a cuyo parecer las fistulae plumbeae «se reservaron principalmente para las conducciones urbanas y para todas aquellas sometidas a presión, pues su mayor resistencia las hacía preferibles, en este caso, a las de cerámica; éstas, de uso más antiguo, eran empleadas generalmente en conducciones relacionadas con el regadío, para las fuentes de jardines o para las cisternas que recogían agua de lluvia». En los conjuntos termales hispanorromanos tenemos constancia de la existencia tanto de caños de terracota como de plomo (GARCÍA-ENTERO, V., 2005: 857).

Balil (1977: 87) llama la atención sobre «la tramoya» que hizo posible surtir de agua a las mansiones rurales de nuestra Península: «Aquí y allá se advierten las cicatrices del viejo emplazamiento de tuberías de plomo».

Con frecuencia, las canalizaciones se disponían sobre una capa de argamasa de cal, arena, polvo de ladrillo y pequeños cantos rodados. Las de la villa de Puente de la Olmilla, en cambio, se apoyan directamente sobre la tierra, por lo que pertenecen al subtipo (de los tres establecidos por FERNÁNDEZ CASADO, C., 1983: 359) de más sencilla colocación: baterías de tejas y ladrillos enterrados desprovistos de galería (aunque en este caso concreto tienen una cubrición de lajas de piedra, tejas y ladrillos, cohesionados con argamasa) y asentados sobre el suelo. Para ligar los empalmes, en Pérgamo se ha comprobado el uso de una mezcla artificial de arena, cal y arcilla con adiciones de hidrófobos, como petróleo, grasas o aceites vegetales (un aglutinante), dando lugar a un material expansivo que al humedecerse rellenaba de un modo perfecto las intersecciones de las piezas tubulares de barro acabadas alternativamente en un entrante y un saliente, ya que se acoplaban por el método de «enchufe y cordón», encajadas mediante el estrangulamiento de uno de sus extremos de borde exvasado. Algunas de las prescripciones vitrubianas (Vitr., De Architectura VIII, 6,8) indicaban que debían tener un grosor, al menos, de dos dedos, que se empleara como sujeción grapas de plo- 
mo, protegiendo los codos con ligaduras de cáñamo, que se aplicara una capa de cal viva empapada en aceite («calce viva ex oleo subacta») e incluso que se añadiera cenizas para calafatear las junturas, antes de introducir el agua. El mortero de cal era muy eficaz para el sellado de las mismas, pues aunque los tubuli fictilibus estuvieran bien ajustados unos con otros, se lograba así una mayor hermeticidad. Como hemos avanzado anteriormente, en Puente de la Olmilla se optó por cubrir las conducciones con argamasa de cal, piedras, fragmentos de tejas y de ladrillos, con el fin de protegerlas por la parte superior. No se trata de una bóveda o canal de mampostería (canalis structilis confornicatus), habitualmente utilizado en el mundo romano (p. ej., en la villa de El Ruedo hay una galería subterránea, parcialmente de obra, construida con «mampuesto cubierto por bóveda conformada en ladrillo», VAQUERIZO GIL, D. y NOGUERA CELDRÁN, J. M., 1997: 28), sino de una sencilla cubierta colocada por encima. Esa mezcla de cal y canto que las recubría posiblemente servía también de efectivo conglomerante para impedir filtraciones, con el propósito de conseguir que las pérdidas de agua en las uniones fueran mínimas o lo más reducidas posible.

Si no se requería presiones elevadas se solía encauzar el agua mediante tubos de cerámica (RUIZ ACEVEDO, J. M. y DELGADO BÉJAR, F., 1991: 51) y, por el contrario, se elegía los de plomo cuando la presión era alta (conducción forzada). En efecto, los canales cerámicos se empleaban en conducciones sin presión (conducciones libres) o de presión reducida, frecuentemente dedicadas a drenajes (FERNÁNDEZ CASADO, C., 1983: 295 y 375), como parece ser el caso de una de las ramificaciones que llegaban hasta el patio de Puente de la Olmilla.

Siempre resultaba conveniente que el manantial, ya se tratara de una fuente o de un río, se hallara a un nivel más alto que las zonas a las que se pretendía proveer de agua. Vitrubio (De Architectura VIII, 108) recomienda un 0,5\% y Plinio (N.H. XXXI, 31) aconseja que la pendiente natural del terreno sea aún más reducida. Concretamente, el primero ${ }^{5}$ la sitúa en medio pie por cien y el naturalista mantiene que debe ser un pie por 4,800 (sobre el cálculo del libramentum y las propuestas de los especialistas antiguos, cfr. MALISSARD, A., 1996: 161-167). La pendiente -mensura declivitatis- adecuada hacía posible que el agua entubada fluyera durante largos trayectos. Eso facilitaría que el agua circulara por su propia presión, aunque ésta fuera escasa, incluso durante el crudo invierno meseteño, evitando así, al discurrir, que se helara. Para impedir que el agua alcanzase demasiada velocidad al ser conducida, ya que su empuje podía resultar arriesgado por el peligro de rotura de las frágiles piezas cerámicas, en ocasiones se prolongaba el recorrido de las canalizaciones: estas alineaciones se alargaban y se introducían recodos en ángulo, trazados en curva, depósitos reguladores, etc. Los cambios topográficos o de sentido provocaban pérdidas de carga, que en estos puntos tenían un nivel de empuje mayor, y a partir de ellos disminuían. Al diseñar estas amplias

5 Vitrubio (De Architectura VIII, 5): «Ahora voy a desarrollar de qué manera conviene realizar las conducciones de agua a los lugares habitados (...). La primera regla es la nivelación. (...) se conocerá la pendiente que hay (...)». 
Uso y disfrute del agua en la Villa Romana de Puente de La Olmilla...

curvas, de longitud mayor de la necesaria para cubrir un tramo concreto, los constructores romanos procuraban corregir los desniveles del terreno que atravesaba el tendido del canal, con el propósito de lograr la vis currendi precisa. Estudiaban el trecho a cubrir buscando el efecto de ralentizar el agua encauzada, pues estaba comprobado que perdían fuerza al chocar en las zonas curvas, circulando después con más lentitud. Fernández Casado (1983: 359) constata que los romanos intentaban conseguir un trazado con un mínimo de alineaciones rectas combinadas con curvas. Así sucede en dos de los tres cordones hidráulicos descubiertos en Puente de la Olmilla, cuyo trazado es curvo, especialmente el que se dirige hacia el Sureste. Éste describe un amplio arco a partir del muro oriental del departamento 25, donde se bifurca el ramal que concluye en el patio. Una vez atraviesa por debajo dicha estructura, en diagonal, cruza el pasillo 32 perpendicularmente respecto al tramo que continúa hacia el Este (Fig. 1).

El declive medio de $0,8 \%$ es estimado como «el justo para el natural discurrir de las aguas» (FAJARDO, P., 1992: 78). Malissard advierte que el agua debía conducirse desde un punto no «demasiado alto, para evitar las interrupciones del suministro durante la estación seca, ni demasiado bajo, para impedir el arrastre de barros y légamos». También explica que el sistema de captación debía adaptarse a la distancia por recorrer y la altura del punto de llegada, para lograr la pendiente óptima sin problemas técnicos relevantes (MALISSARD, A., 1996: 156, 161-162).

Hay que tener presente las condiciones topográficas del emplazamiento de esta villa de Albaladejo, en cuanto a la relación entre la mensura declivitatis y la presión del agua, que aquí no debía de ser demasiado alta, dado que la diferencia de cota entre el núcleo de la residencia (el patio-peristilo) y la zona nororiental (el punto más bajo) no es muy acusada.

\section{SÍNTESIS FINAL}

Los tres canales cerámicos previamente descritos forman parte de una red más amplia que aprovisionaría de agua a este enclave, pero al discurrir por el subsuelo no es posible rastrear a simple vista sus trayectos y, al extralimitar el espacio excavado, no conocemos su recorrido completo. De hecho, el hallazgo de fragmentos cerámicos de otras posibles canalizaciones diseminados a flor de suelo por el extenso campo de ruinas es un indicio de la probable existencia de otros cordones hidráulicos de enlace con distintas dependencias de la villa.

Tratando de sintetizar cuanto hemos expuesto en páginas anteriores, insistiremos en el hecho determinante de que el paraje disponía de agua proveniente de un regato cercano. Como por lo demás no ha dejado de ser repetidamente señalado, este elemento, esencial para cualquier clase de asentamiento, era doblemente imprescindible en uno de tipo agropecuario, razón por la cual un complejo rural como éste debía tener asegurado un aporte constante y esa circunstancia se debió de tener muy en cuenta al erigirlo en los terrenos de Puente de la Olmilla, 
condicionando, entre otros factores, su ubicación. No obstante recalcar lo evidente, era un requisito básico para poder subsistir incluso durante el verano, que entonces, como ahora, adolecería de un bajo nivel pluviométrico -recordemos que se halla bajo la isoyeta 600-. En este sentido, las lluvias son un fenómeno crucial para la supervivencia de una instalación rústica, fundamentalmente dependiente de la fertilidad agrícola. Respecto al acopio de este preciado recurso hídrico, aunque no hemos localizado dentro del área excavada ninguna pileta o depósito receptor del agua pluvial ni cisternas donde se vertiera y conservara el agua procedente del Arroyo de la Bola, creemos muy probable su existencia, dado que, habida cuenta su efímera abundancia, contar con una reserva permitiría a este establecimiento persistir sin problemas de esa clase durante los meses más calurosos, cuando seguramente se moderaría el caudal de ese, temporalmente, frágil arroyuelo, y así no sufriría tan intensamente la sequía estacional u otras irregularidades climáticas, causantes de momentos de gran dureza medioambiental. Con todo, aunque no conocemos el régimen de lluvias habitual en aquella época, posiblemente era más alto que en nuestros días, como sugerimos al comienzo de este trabajo.

Así pues, recapitulando, la cuestión del agua estaba perfectamente resuelta en esta villa, tanto en lo concerniente a su traída, como a su distribución interna, conseguida gracias a la actividad desplegada en la construcción de diversas ramificaciones que surtían de ella a sus habitantes. Por lo general, esto únicamente sucedía en las casas ricas de las grandes ciudades y en algunas villae rusticae (donde además de agua corriente, para atender a las necesidades domésticas, también la encauzaban para la irrigación de los huertos, jardines y campos cultivables), como ésta de Puente de la Olmilla, la de Carranque (Toledo), la de Baños de Valdearados (Burgos), la de El Ruedo (Almedinilla, Córdoba), etc.

El agua, en definitiva, no sólo servía para el consumo de personas y animales, sino que tenía las más variadas utilidades ya en la Antigüedad romana: termales, ornamentales, industriales, etc.

\section{Abreviaturas:}

*AEspA = Archivo Español de Arqueología

$C N A=$ Congreso Nacional de Arqueología

CMRE = Corpus de Mosaicos Romanos de España

MCV = Mèlanges de la Casa de Velázquez

$\mathrm{NAH}=$ Noticiario Arqueológico Hispánico 
Uso y disfrute del agua en la Villa Romana de Puente de La Olmilla...

\section{BIBLIOGRAFÍA}

ADAM, J. P. (1984): La construction romaine. Materiaux et techniques, París.

ALARÇAO, J., ETIENNE, R. y MAYET, F. (1990): Les villes romaines de Sao Cucufate (Portugal) I y II, París.

ALBIACH DESCALS, R. et alii (2009): «El agua sacra y su vinculación con el origen y el desarrollo urbano de una fundación romana. El santuario (¿Asklepeion?) de Valentia (Hispania)», Anejos de AEspA XLV, Mérida, 417-437.

ARENILLAS PARRA, M. et alii (2009): El abastecimiento de agua a Toledo en época romana, Confederación Hidrográfica del Tajo, Toledo.

BALIL ILLANA, A. (1977): «Fuentes y fontanas romanas de la Península Ibérica», Symposium de Arqueología romana, Barcelona, 77-89.

BELTRÁN MARTÍNEZ, A. (1975): «El tubo de plomo del frigidarium de las termas de los Bañales (Uncastillo, Zaragoza)», XIV CNA, Vitoria, 1.049-1.054.

- (1977): «Las obras hidráulicas de los Bañales (Uncastillo, Zaragoza)», Symposium de Arqueología romana, Barcelona, 91-129.

BERTACCHI, L. (1983): «Ricomposizione del mosaico opitergino con villa rustica», en Mosaïque. Recueil d'hommages à Henri Stern, París, 65-73.

BLÁZQUEZ MARTÍNEZ, J. M. (1977): «La administración del agua en la Hispania romana», Symposium de Arqueología romana, Barcelona, 147-161.

- (1981): «Poblado de esclavos mineros en Fuenteobejuna», Revista de Arqueología, Madrid, 7-12.

- (1982): Mosaicos romanos de la Real Academia de la Historia, Ciudad Real, Toledo, Madrid y Cuenca, CMRE V, Madrid.

- (1982-83): «Noticia sobre las excavaciones arqueológicas en la mina republicana de La Loba (Fuenteobejuna, Córdoba)», Corduba Archaeologica 12, Córdoba, 28-39.

- (2001): «Los jardines de la Hispania romana», Historia de los parques y jardines en España, Obra Completa, 21-35.

BONSOR, G. (1899): «Les colonies agricoles pré-romaines de la Vallée du Bétis», Revue Archéologique XXXV, París, 126-268.

CASTELO RUANO, R. et alii (1997): «La villa romana de El Saucedo (Talavera la Nueva, Toledo): construcciones termales y recientes hallazgos monetarios», Boletín Asociación Española de Amigos de la Arqueología 37, Madrid, 63-98.

- (2006): «El Saucedo (Talavera la Nueva, Toledo). Un ejemplo de villa bajoimperial en la provincia de la Lusitania», Anejos de AEspA XXXIX, Madrid, 173-196.

CERRILlO, E., CERRILLO, F. J., ONGIL, M. I., HERRERA, G. y ALVARADO, M. de (1986): «Espacio doméstico y espacio de prestigio», Arqueología Espacial 10, Teruel, 121-134.

CORCHADO SORIANO, M. (1974): «Albaladejo», Corpus de los castillos medievales de Castilla, Espinosa y Martín-Artajo (coord.), Bilbao, 31-32.

CORTES ÁLVAREZ DE MIRANDA, J. (1975): «Algunas piezas de arqueología romana de Saldaña», Sautuola I, Santander, 199-201.

DAREMBERG, CH.- SAGLIO- POTTIER, EDM (1969): Dictionnaire des Antiquités grecques et romaines, Austria.

DÍEZ-CORONEL y MONTULL, L. (1968): «Una bodega romana en Balaguer (Lérida)», CANXI, 774-783.

FAJARDO, P. (1992): «El oro movió montañas», MOPT, Madrid, 75-79.

FERNÁNDEZ CASADO, C. (1949): «La conducción romana de aguas de Almuñécar», AEspA 77, Madrid, 313-333.

- (1983): Ingeniería hidráulica romana, Madrid.

FERNÁNDEZ CASTRO, M. C. (1978): «Aspectos arquitectónicos y musivarios de las villas romanas en Andalucía», I Congreso de Historia de Andalucía. Andalucía en la Antigüedad (1976), Córdoba, 309-331. 
- (1982): Las villas romanas en España, Madrid.

FERNÁNDEZ RODRÍGUEZ, M. y GARCÍA BUENO, C. (1993): «La minería romana de época republicana en Sierra Morena: el poblado de Valderrepisa (Fuencaliente, Ciudad Real)», MCV XXIX, Madrid, 25-50.

- (1994): «El poblado romano de Valderrepisa», Arqueología en Ciudad Real, Junta de Comunidades de Castilla-La Mancha, Talavera (Toledo), 195-210.

- (1997): «Valderrepisa: un ejemplo de aplicación de la Ley de Patrimonio Histórico-Arqueológico en un yacimiento metalúrgico romano", Actas de la la Sesión Científica sobre Patrimonio Minero Metalúrgico (Almadén, 1996), Cuenca, 55-62.

FIGUERAS PACHECO, F. (1971): Relación de hallazgos arqueológicos en el Tosal de Manises (Alicante) 1933-1935, Valencia.

FORBES, R. J. (1964): Studies in ancient technology I, Leiden.

GARCÍA BUENO, C. (1994): «Mosaicos de la villa romana de Puente de la Olmilla (Albaladejo, C. Real)», Veleia 11, Vitoria, 95-116.

- (2000): «Problemática de la arqueología romana en la provincia de Ciudad Real: la villa de Puente de la Olmilla (Albaladejo), Benítez de Lugo Enrich, L. (coord.): El patrimonio arqueológico de Ciudad Real, Valdepeñas (C. Real), 191-203.

- (2001): «Apuntes para el estudio de los mosaicos de la villa romana de Puente de la Olmilla (Albaladejo, Ciudad Real)», Pátina 10 y 11, Madrid, 212-217.

GARCÍA BUENO, C. y FERNÁNDEZ RODRÍGUEZ, M. (1995): «Minería y metalurgia en Sierra Morena. El poblado romano republicano de Valderrepisa», Revista de Arqueología 170, Madrid, 24-31.

— (1997): «La fundición romana de Valderrepisa (Fuencaliente, Ciudad Real): alteración y protección de un asentamiento metalúrgico», Actas de la la Sesión Científica sobre Patrimonio Minero Metalúrgico (Almadén, 1996), Cuenca, 193-198.

GARCÍA-ENTERO, V. (2005): Los balnea domésticos -ámbito rural y urbano- en la Hispania romana, Anejos de AEspA XXXVII, Madrid.

GORGES, J.-G. (1979): Les villas hispano-romaines. Inventaire et problématique archéologiques, París.

- (1992-1993): «La place de l'eau dans les villas luso-romaines: de l'hydraulique domestique à l'hydraulique rural», Studia Historica X-XI, Salamanca, 253-272.

HALKIN, L. (1965): Les esclaves publics chez les romains, Roma, 1965.

HIDALGO PRIETO, R. (1996): «Sobre la interpretación de las termas de Cercadilla (Córdoba)", Habis 27, Sevilla, 189-203.

HERVÁS y BUENDÍA, I. (1890): Diccionario Histórico Geográfico de la provincia de C. Real, Ciudad Real.

LACORT NAVARRO, P. J. (1989): «Obras hidráulicas e implantación rural romana en la campiña de Córdoba», I Coloquio de Historia y Medio Físico, Almería, 361-404.

- (1991): «Acueducto romano en el término de Fuenteobejuna (Córdoba). Abastecimiento de agua a Mellaria», Anales de Arqueología cordobesa 2, Córdoba, 363-370.

LEVI, D. (1947): Antioch mosaic pavements, I y II, Princeton.

LÓPEZ MONTEAGUDO, G. (1997): «Termas y tecnología de las aguas. Testimonios musivos», Termalismo Antiguo. Actas del I Congreso Peninsular (Arnedillo - La Rioja 1996), Madrid, 453-466.

- (2006-2007): «Nuevos documentos del mosaico emeritense de Opora», Anas 19-20, $185-222$.

- (2010): «Nuevos mosaicos emeritenses con inscripciones», UAM, Col. de Estudios 143, Madrid, 235-250.

LOZA AZUAGA, M. I. (1994): «El agua en los teatros hispanorromanos: elementos escultóricos», Habis 25, Sevilla, 263-283.

MALISSARD, A. (1996): Los romanos y el agua, Barcelona.

MANGAS MANJARRÉS, J. (1981): Historia de España I, Madrid.

MARINÉ ISIDRO, M. (1984): «Las termas de la villa de Cuevas de Soria», Actas del I Symposium de Arqueología soriana, Soria, 403-411. 
Uso y disfrute del agua en la Villa Romana de Puente de La Olmilla...

MAYER, M. y RODÁ, I. (1977): «El abastecimiento de aguas de la Barcelona romana. Reconstrucción de su trazado", Symposium de Arqueología romana, Barcelona, 265-283.

MEZQUÍRIZ IRUJO, M. A. (1979): «El acueducto de Alcanadre-Lodosa», Trabajos de Arqueología Navarra 1, Pamplona, 139-145.

MEZQUÍRIZ IRUJO, M. A. y UNZU URMENETA, M. (1985): «De hidráulica romana: el abastecimiento de agua a la ciudad romana de Andelos», Trabajos de Arqueología Navarra 7, Pamplona, 237-254.

MONTAÑÉS CABALLERO, S. (1993): «Ingeniería hidráulica romana en Medina Sidonia (Cádiz)», Revista de Arqueología 146, Madrid, 32-39.

OREJAS SACO DEL VALLE, A. (1989): «Obras hidráulicas romanas y explotación del territorio en la provincia de Toledo", I Coloquio de Historia y Medio Físico, Almería, 45-67.

PALOMEQUE TORRES, A. (1955): «La villa romana de la finca de Las Tamujas (término de Malpica de Tajo, Toledo)», AEspA XXVIII, Madrid, 305-317.

- (1963): «Memoria de la campaña de excavaciones realizada en septiembre de 1962 en la villa romana de Las Tamujas (Malpica de Tajo, Toledo), NAH VII, Madrid, 198 ss.

PASCOLINI, A. (1985): Usanze e tecniche nell' edilizia degli antichi romani, Armando, Roma.

PASSI PITCHER, L. (1996): Bedriacum. Ricerche archeologiche a calvatone, 1.1, Studi sul vicus e sull'ager, Milán.

PUERTAS TRICAS, R. (1986-87): «Los hallazgos arqueológicos de Torreblanca del Sol (Fuengirola), Mainake VIII-IX, Málaga, 145-148.

PUIG OCHOA, M. R. (1979): «Pintura romana de Albaladejo», XV CNA (Lugo, 1977), Zaragoza, 923-930.

PUIG OCHOA, M. R. y MONTANYA MALUQUER, R. (1975): «Mosaicos de la villa romana de Puente de la Olmilla (Albaladejo, Ciudad Real)», Pyrenae XI, Barcelona, 133-143.

— (1978): «La «villa» romana de Puente de la Olmilla», 20.000 km², Rev. de la Diputación Provincial 13, Ciudad Real, 9-10.

RODRÍGUEZ NEILA, F. J. (1988): «Aqua pública y política municipal romana», Gerión 6, Madrid, 223-252.

ROMANELLI, P. (1970): Topografia e Archeologia dell' Africa Romana, Turín.

RUIZ ACEVEDO, J. M. y DELGADO BÉJAR, F. (1991): El agua en las ciudades de la Bética, Sevilla.

- (1992): «Abastecimiento de agua a las ciudades hispanorromanas», Revista de Arqueología 139, Madrid, 36-47.

SÁENZ RIDRUEJO, F. (1977): «Observaciones técnicas sobre el abastecimiento romano de aguas a Tarragona", Symposium de Arqueología romana, Barcelona, 351-358.

SÁEZ FERNÁNDEZ, P. (1987): Agricultura romana de la Bética, I, Sevilla.

SAN NICOLÁS PEDRAZ, P. (1994): «Mosaicos y espacio en la villa romana de Fuente Álamo (Córdoba, España)", X Convegno di Studi su L'Africa romana, Sassari, 1.2891.304.

— (1997): «Los espacios ajardinados en la musivaria romana», Espacio, Tiempo y Forma II/10, Madrid, 137-175.

— (1998): «Arquitectura rural en los Mosaicos Hispanos», XII Convegno di Studi su L'Africa romana, Sassari, 891-906.

- (2004-2005): «Seres mitológicos y figuras alegóricas en los mosaicos romanos de Hispania en relación con el agua», Espacio, Tiempo y Forma II/17-18, Madrid, 301-333.

SÁNCHEZ ABAL, J. L. (1977): «Obra hidráulica romana en la provincia de Toledo (pantano de Alcantarilla)», Symposium de Arqueología romana, Barcelona, 359-366.

SCHULTEN, A. (1963): Geografía y etnografía antiguas de la Península Ibérica II, Madrid.

SERRA RÁFOLS, J. de C. (1947): «Algunos elementos que puede aportar la Arqueología para el conocimiento del estado social y de la economía rural hispanorromana», Revista Internacional de Sociología 5, Madrid, 451-466.

- (1952): La villa romana de La Dehesa de La Cocosa (Badajoz). 
STYLOW, A. U. (1986): «Apuntes sobre epigrafía de época flavia en Hispania», Gerión 4, Madrid, 285-311.

VAQUERIZO GIL, D. (1990): «La villa romana de «El Ruedo» (Almedinilla, Córdoba)», AEspA 63, Madrid.

VAQUERIZO GIL, D. y NOGUERA CELDRÁN, J. M. (1997): La villa de El Ruedo (Almedinilla, Córdoba). Decoración escultórica e interpretación, Murcia.

VENTURA, F.S. (1989): «La agricultura de regadío durante la Antigüedad tardía en el Sur de la Península Ibérica», I Coloquio de Historia y Medio Físico, Almería, 405. 